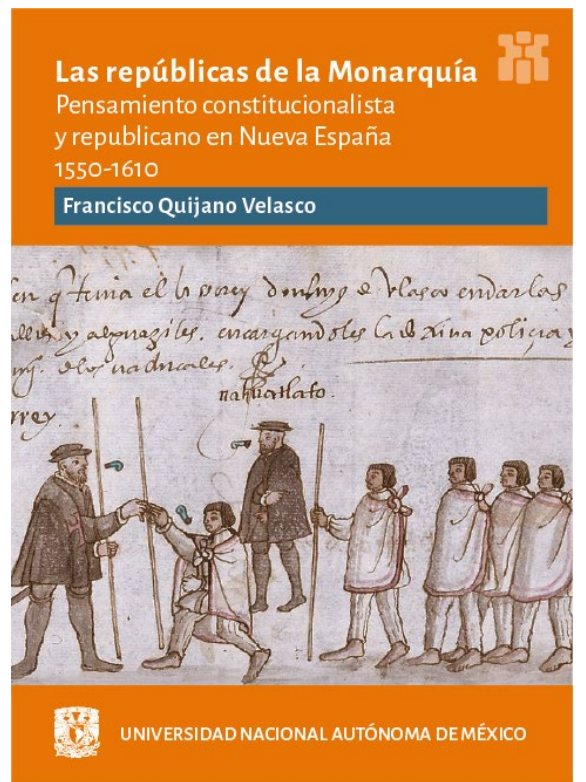

Francisco Quijano Velasco

"Recapitulación y conclusiones"

p. 263-279

Las repúblicas de la Monarquía

Pensamiento constitucionalista y republicano en

Nueva España, 1550-1610

Francisco Quijano Velasco (autor)

\title{
México
}

Universidad Nacional Autónoma de México, Instituto de Investigaciones Históricas

llustraciones

(Historia Novohispana 104)

Primera edición impresa: 2017

Primera edición electrónica en PDF: 2017

Primera edición electrónica en PDF con ISBN: 2018

ISBN de PDF 978-607-30-0558-6

http://ru.historicas.unam.mx

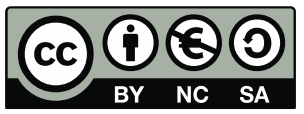

Licencia Creative Commons Atribución-NoComercial-Compartirlgual 4.0

Internacional

https://creativecommons.org/licenses/by-nc-sa/4.0/

2019: Universidad Nacional Autónoma de México, Instituto de Investigaciones Históricas. Algunos derechos reservados. Consulte los términos de uso en http://ru.historicas.unam.mx.

Se autoriza la consulta, descarga y reproducción con fines académicos y no comerciales o de lucro, siempre y cuando se cite la fuente completa y su dirección electrónica. Para usos con otros fines se requiere autorización expresa de la institución.

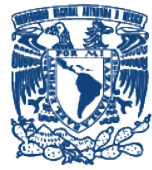




\section{RECAPITULACIÓN Y CONCLUSIONES}

El mundo hispánico de la Modernidad temprana estuvo marcado por la diversidad, presente en su composición étnica, territorial, institucional, intelectual. Esa entidad histórico-cultural, conformada inicialmente por una península ibérica de por sí diversa, a lo largo del siglo XVI se volvió más compleja con la anexión de territorios y pueblos de Europa y de las Indias occidentales y orientales. El sentido de unidad estaba fundado en la Monarquía - con sus atributos civiles y religiosos-, que proveía una autoridad común a las múltiples naciones y repúblicas. En la escena política, la historia del ámbito hispánico de los siglos XVI y XVII es la historia de las relaciones entre los distintos cuerpos que conformaban la Monarquía: la Corona y sus reinos, las ciudades y pueblos constituidos en cabildos, la Iglesia organizada en obispados y provincias religiosas. La búsqueda por defender intereses comunes y específicos de cada una de sus partes llevó a que la vida política de la Monarquía estuviera marcada por el conflicto y la negociación.

Como hemos visto a lo largo de este libro, en el terreno del pensamiento político se manifestó también esta diversidad. Contrario a lo que la historiografía tiende a presentar, durante los siglos XVI y XVII existieron dentro del ámbito hispanoamericano distintas tradiciones intelectuales que plantearon respuestas diversas - y en algunos casos antagónicas - a los problemas políticos de su tiempo. Entre éstas se podrían mencionar al humanismo cívico, la literatura de carácter histórico, los tratados de gobierno y razón de Estado, los espejos de príncipes, el arbitrismo y la escolástica.

Pese a las diferencias en sus intereses, objetivos y lenguajes, al tratar temas relacionados con el gobierno de la república los autores enmarcados en estas tradiciones fijaron su posición ante algunos problemas comunes y centrales en la reflexión política 
de la época, como el origen del poder o los límites de la autoridad. A partir de la postura que asumieron en torno a ellos, es posible distinguir dos tendencias. Por un lado, quienes buscaron defender los derechos de la Corona frente a las repúblicas, excluyendo a la comunidad de sus explicaciones sobre el origen y la legitimación del dominio político, así como descartando la posibilidad de que, mediante su voluntad, pudieran imponer límites al ejercicio del poder. Esta perspectiva puede ser descrita como absolutista y es precisamente la que la historiografía tradicional o la de corte liberal tiende a presentar como hegemónica en el mundo hispanoamericano de los siglos XVI y XVII. Los presupuestos de tendencia absolutista, pese a no ser los únicos que se presentaron en las discusiones de la época, sí tuvieron una presencia central dentro del ámbito intelectual y fueron recurrentes entre los autores de la llamada razón de Estado, de los espejos de príncipes y entre un sector de los juristas y canonistas escolásticos. Asimismo, el lenguaje administrativo empleado por la Corona y sus agentes recuperó también principios de carácter absolutista.

En un sentido opuesto a esta tendencia, otros autores pusieron en el centro de sus teorías sobre la conformación y el ejercicio del poder a la comunidad constituida como un cuerpo político, reivindicando con ello los derechos de las repúblicas frente a los de la Corona. Esta vertiente es la que denomino en este trabajo como republicana o constitucionalista. Como se mostró en los primeros dos capítulos, al igual que en otras regiones de Europa, personajes que vivieron en el mundo hispano tuvieron a su disposición y utilizaron principios, conceptos y teorías que dentro de la historiografía se identifican como constitucionalistas o republicanos. Estos principios, al igual que en otras latitudes, fueron recuperados de fuentes clásicas — principalmente Aristóteles, Cicerón y el derecho romano - y utilizados por autores vinculados al humanismo cívico, al arbitrismo y a la llamada Segunda escolástica. Esta última destacó en el ámbito hispánico de la temprana Modernidad por la fuerte presencia que mantuvo en las universidades y en las discusiones políticas de la época.

Si tuviéramos que describir en términos generales el desarrollo de estas dos tendencias, podríamos señalar que conforme 
avanzaron las décadas del siglo XVII la vertiente absolutista cobró más fuerza en el panorama intelectual hispánico, mientras que las tradiciones que recuperaron principios republicanos o constitucionalistas o bien se difuminaron, como en el caso del humanismo cívico, o se moderaron en sus argumentos, como sucedió con la Segunda escolástica. Esto fue resultado, por un lado, de la búsqueda de fortalecimiento del poder real dentro de los reinos ibéricos, particularmente Castilla, que se manifestó en la pretensión de la Corona de centralizar y monopolizar facultades jurídicas y políticas que se mantenían repartidas entre diversas corporaciones. Dicha búsqueda estuvo acompañada del desarrollo de tradiciones intelectuales absolutistas, particularmente los tratados de razón de Estado, que justificaron o legitimaron dichas pretensiones. De forma paralela, el pensamiento político hispánico se vio afectado por un proceso sistemático de limitación de fuentes que fueron consideradas heterodoxas en el contexto de la Contrarreforma, muchas de ellas importantes para la argumentación constitucionalista o republicana. Esto contribuyó a que, en el ámbito hispánico, las respuestas a las pretensiones centralizadoras y absolutistas de la Corona y a la argumentación que en favor de ellas se hizo en el terreno intelectual se presentaran tímidas o moderadas en comparación con como se habían desarrollado durante los dos primeros dos tercios del siglo XVI o con como se presentó en otras regiones de Europa durante la segunda mitad del siglo XVII.

Pero, ¿qué sucedió en el ámbito hispanoamericano y particularmente en los reinos y provincias que conformaban a la Nueva España? ¿Qué formas adoptaron en estas latitudes las expresiones republicanas y constitucionalistas? A partir de los estudios de caso puedo ahora responder a estos interrogantes planteados en los primeros dos capítulos del libro. Como vimos, las discusiones y los debates en torno al dominio español sobre América conformaron uno de los principales espacios controversiales del mundo hispánico de la temprana Modernidad, y en él se manifestaron varios de los lenguajes arriba mencionados, así como el desarrollo histórico de las tendencias absolutistas y constitucionalistas. Dentro de las tradiciones que intervinieron, la escolástica —en sus expresiones teológicas y jurídicas - fue la que más contribuyó a 
la discusión de los problemas americanos. Mientras que desde el derecho se presentaron las defensas más sólidas del dominio colonial de la Corona sobre las Indias, un grupo de teólogos de la Segunda escolástica desarrolló una serie de teorías republicanas y constitucionalistas para defender los derechos de las repúblicas indianas dentro de la Monarquía. Así, en un contexto controversial muy distinto al de otros debates políticos europeos en los que se desplegaron argumentos republicanos o constitucionalistas - pensemos, por ejemplo, en el de la libertad de las ciudades italianas, el de las guerras de religión de fines del siglo XVI o el de las revoluciones inglesa y de los Países Bajos en el siglo XVII-, encontramos en Hispanoamérica algunos principios y presupuestos que bien podrían describirse como expresiones de dichas tradiciones.

A lo largo del libro mostré cómo en los textos de Alonso de la Veracruz, Bartolomé de Las Casas y Juan Zapata y Sandoval aparecen expresiones de lo que en la historiografía se denomina pensamiento constitucionalista y republicano. Entre ellas destacan la explicación popular del origen del poder, la búsqueda de establecer límites puntuales a la autoridad, el uso del concepto de libertad como sinónimo de independencia, el bien común concebido como el fin de la sociedad y la defensa de la participación de los ciudadanos en su gobierno. Lo anterior no significa que dichos autores presentaran en sus tratados teorías políticas acabadas, coherentes y sistemáticas sobre todos los presupuestos mencionados. Tampoco que su pensamiento pueda ubicarse dentro de una trayectoria de ilación y continuidad, bajo un principio de recepción e influencia, con los pensadores que los historiadores del republicanismo o el constitucionalismo de otras latitudes suelen postular como sus más destacados representantes. Lo que se muestra en este estudio es, en cambio, cómo los autores analizados acudieron a las mismas fuentes que los tradicionalmente reconocidos por la historiografía del constitucionalismo y el republicanismo para recuperar paralelamente conceptos, principios y teorías similares, los cuales fueron empleados para argumentar en contextos polémicos diferentes, sobre problemas diferentes y en oposición a tradiciones políticas diferentes. Esto llevó a que existieran importantes variantes en la forma en que Alonso de la 
Veracruz, Bartolomé de Las Casas y Juan Zapata y Sandoval utilizaron los principios constitucionalistas y republicanos descritos en el primer capítulo con respecto a otros pensadores contemporáneos, por ejemplo, Nicolás Maquiavelo o Theodore Beza. Así, como vimos, una característica del pensamiento de los autores en cuestión fue su predilección por la monarquía como forma de gobierno, particularmente la monarquía mixta. Pero, sin duda, el sello distintivo fue su interés en analizar las relaciones de dominio entre naciones y el haberse presentado como las primeras manifestaciones de un republicanismo y constitucionalismo anticolonial. Este anticolonialismo se manifestó de dos formas distintas: por un lado, en la denuncia de la conquista y la dominación española sobre los pueblos indígenas, en la reivindicación de la autonomía de éstos y de las prácticas e instituciones que permitieron a las repúblicas de indios organizarse como cuerpos políticos. Por otro, en las reacciones de los criollos ante la centralización del poder en la Corona y la introducción de funcionarios peninsulares, y a favor de la preservación de los privilegios y el autogobierno de las élites novohispanas. No obstante, como vimos, esta última forma de pensamiento se presentó al mismo tiempo como colonialista al defender la subordinación de los pueblos indígenas a los descendientes de conquistadores y primeros colonos.

Ahora bien, una vez que se acepta la viabilidad de utilizar las categorías historiográficas de republicanismo y constitucionalismo para describir el pensamiento de un grupo de autores novohispanos, es conveniente señalar las ventajas que esto tiene. Sobre todo porque, como se mencionó en el primer capítulo, el uso de dichos conceptos en la historia intelectual no ha estado exento de críticas. En este sentido, considero que recurrir a estas categorías puede ser un aporte a la historiografía cuando menos en dos sentidos distintos. Por un lado, permite hacer visible la presencia de lenguajes políticos que defendían el origen popular del poder, la participación de la república en la toma de decisiones o la restricción a la autoridad política en la Nueva España del siglo XVI. Esto es una contribución de gran relevancia para el conocimiento y la comprensión de la historia política, intelectual e institucional del periodo colonial. Al mostrar una mayor diversidad 
de actores, lenguajes y tradiciones que convivieron en esta región de la Monarquía durante la temprana Modernidad, normalmente reducida a tradiciones de pensamiento teocrático y absolutista, pueden surgir nuevas lecturas sobre procesos históricos vinculados con el desarrollo de los reinos y las provincias de Nueva España, como la conformación de instituciones y espacios de acción política o la construcción de identidades de los grupos que habitaban en ella.

El otro aporte es enriquecer la discusión sobre los contenidos de las categorías mismas de republicanismo y constitucionalismo. Si partimos de que no existen formas ideales o acabadas de dichas tradiciones, el analizar "nuevos" espacios en que los principios asociados a ellas se manifestaron en el pasado permite hacer una valoración más amplia sobre su sentido, utilidad y condiciones de posibilidad. Mostrar que en un ámbito poco esperado, como es el caso de la Nueva España, se utilizaron estos principios debe llevarnos necesariamente a replantear asuntos centrales sobre la interpretación que hacemos del desarrollo histórico de las tradiciones mencionadas. En este sentido, en vez de hablar de un "momento" republicano o constitucionalista, en el que claramente se puede trazar la ruta que siguió una tradición intelectual en el mundo occidental, como lo propone Pocock, conviene más pensar en las condiciones que hicieron posible la articulación de ideas y discursos similares desplegados en distintos contextos por personajes desconocidos entre sí. Así, el republicanismo y el constitucionalismo de la temprana Modernidad, más que tradiciones intelectuales concebidas bajo un principio de linajes - con sus ramas puras y bastardas-, tendrían que ser vistos como lenguajes de amplia difusión cuya existencia fue posible gracias a la circulación de un reducido cuerpo de textos y fuentes comunes. Fue la presencia de estos lenguajes lo que permitió que en diversos espacios de discusión se articularan discursos en cuyos fundamentos se encontraban teorías sobre el origen popular del poder, el bien común como el fin de la sociedad política, la libertad como no dependencia o la participación de los ciudadanos en el gobierno.

En este sentido, si aceptamos hablar de la presencia de lenguajes constitucionalistas o republicanos en la Nueva España del 
siglo XVI, es a condición de no suponer que se trata de adaptaciones de tradiciones predefinidas y existentes en algún otro lugar. De lo que se puede hablar, en cambio, es del uso de un conjunto de fuentes, vocabularios y presupuestos específicos que aparece en un nuevo espacio político, cuyo desarrollo relativamente autónomo -y no por ello menos significativo- respondió a la especificidad del contexto polémico en donde se desplegó. Adoptar esta premisa analítica implica insertar el pensamiento político de las colonias iberoamericanas no como una desviación o tropicalización del pensamiento político occidental, sino como parte constitutiva del mismo. En sentido figurado, se podría decir que, al recurrir a las categorías de republicanismo y constitucionalismo para describir el pensamiento de los autores aquí analizados, se recobra en un contexto historiográfico su carácter anticolonial. Mostrar cómo estas categorías reservadas tradicionalmente para hablar del pensamiento europeo son operativas en el ámbito indiano, sin tener que explicar su relación en términos de pérdida, desviación o falta de originalidad, es una forma de descolonizar la historia del pensamiento político hispanoamericano.

Recapitulemos ahora la manera en que Alonso de la Veracruz, Bartolomé de Las Casas y Juan Zapata y Sandoval articularon sus discursos a partir de lo que denomino, considerando lo anterior, lenguajes constitucionalistas y republicanos.

Como vimos, Alonso de la Veracruz se formó entre los teólogos más conocidos de la primera etapa de la Segunda escolástica y en sus tratados utiliza muchos principios de la filosofía aristotélica y tomista que la caracterizó. El agustino desarrolló su pensamiento a partir de la teoría tomista de la ley natural y de conceptos como el de dominio y justicia, vinculados a una concepción esencialmente objetiva del derecho. No obstante, recuperó también una serie de presupuestos del nominalismo, que se hace patente en su explicación sobre el origen del poder. A diferencia de los otros autores de la Segunda escolástica —incluyendo a Bartolomé de Las Casas-, Veracruz consideraba que era la comunidad de los hombres la que creaba el poder político, por lo que éste no existía por derecho natural o divino. Con ello, reconocía un carácter histórico y contingente en la fundación de las 
repúblicas y otorgaba a la comunidad mayor capacidad para definir el rumbo de la vida en común. Vinculado a este principio, Veracruz desarrollaría lo que considero el elemento más significativo de su pensamiento: su postura ante el problema de la variabilidad del derecho natural. Nuevamente, integrando elementos del tomismo y el nominalismo, Veracruz desarrolló una teoría mediante la cual justificaba la legitimidad de diferentes interpretaciones del derecho natural, en sus segundos principios, a través de una racionalidad adaptada a las circunstancias.

Ambas particularidades de su pensamiento, que debatían en el ámbito teórico con posturas de otros autores escolásticos, surgieron en función de lo que el autor estaba haciendo con sus tratados dentro de la controversia indiana. Veracruz fue testigo del temprano proceso de incorporación de los señoríos indígenas a la Monarquía hispánica, que tuvo lugar durante las primeras tres o cuatro décadas de la vida política de los reinos americanos. Asimismo, presenció el desplazamiento de los antiguos señores indígenas y sus linajes en el orden político, basado en la limitación de sus privilegios tributarios y jurisdiccionales, que comenzó a ocurrir a mediados del siglo XVI y que culminó con la introducción generalizada del cabildo indígena como forma de gobierno. En este largo proceso, Veracruz apoyó los intereses de los señores indígenas y lo que estableció en sus tratados fue, precisamente, una defensa de la continuidad de sus gobiernos, del poder para disponer de sus propiedades y cobrar impuestos, del mantenimiento de sus dominios. Para el agustino, las repúblicas y los señoríos indígenas habían sido instituidos por los diversos pueblos americanos, los cuales no sólo habían transferido la potestad de dominio a sus gobernantes sino que eran los creadores de sus propias jurisdicciones. La legitimidad de los príncipes y señores indígenas residía en la voluntad de las comunidades que los habían instituido y, por lo tanto, no podían ser removidos sin su autorización. A partir de su teoría sobre la variabilidad del derecho natural, rechazó los argumentos de quienes veían barbarie en las prácticas políticas y en las costumbres de los pueblos indígenas. Para él, a pesar de las diferencias en relación con las europeas, tanto las formas de gobierno como los usos y costumbres de dichas 
sociedades eran legítimos en tanto que estaban encaminados al mantenimiento de la vida y al bien común. Por todo esto, para que la Corona española pudiera ejercer el gobierno supremo sobre las Indias era necesario que se mantuviera el dominio — como propiedad y como jurisdicción- de los indígenas y sus legítimos señores. Así pues, de fundarse un nuevo cuerpo político, éste debía adoptar la forma de un gobierno mixto en el que los reinos americanos estuvieran compuestos por repúblicas indígenas regidas por sus propias leyes y sus propios gobernantes.

Por su parte, Bartolomé de Las Casas desarrolló una filosofía en la que recuperó, sobre todo en su madurez intelectual, elementos de las tradiciones aristotélico-tomista y neorromana. Su acción política estuvo vinculada más a los altos círculos del poder civil y eclesiástico que al ámbito universitario, por lo que sus tratados presentan una dimensión más pragmática que la mayoría de los textos escolásticos. El interés tan inmediato en modificar las instituciones y prácticas políticas de su tiempo llevó a Las Casas a echar mano de un amplio arsenal de teorías y conceptos provenientes de tradiciones diversas. Al igual que Veracruz, para Las Casas los gobernantes ejercían el poder político porque la república había decidido transferirles la potestad con el único fin de buscar el bien común. Aunque no sostenía que dicho poder había sido creado por los hombres, como lo hacía Veracruz, sí otorgaba un mayor peso a la voluntad de la comunidad como límite de la autoridad, equiparándola en importancia con el derecho natural. Siguiendo un principio que la historiografía reconoce como fundamental dentro del republicanismo, Las Casas argumentó que la comunidad mantenía el dominio sobre sí misma una vez establecida la autoridad política, lo cual convertía a los gobernantes en rectores y administradores y no en príncipes soberanos como los concebía la tradición de la razón de Estado.

Pero el elemento más significativo del pensamiento lascasiano fue, en mi opinión, el uso que hizo de la teoría republicana de la libertad dentro de la controversia indiana. Al igual que para los autores del humanismo cívico, para el dominico la libertad en un contexto político era, ante todo, la ausencia de dependencia, el no estar sujeto a la voluntad arbitraria de alguien más. 
Integrando en su pensamiento el lenguaje de los derechos subjetivos, consideró dicha libertad como un derecho ínsito del hombre y de las sociedades que constituía. Para Las Casas, este argumento bastaba por sí mismo para contradecir cualquier pretensión de dominio de la Corona española sobre América que no estuviese basada en la libre aceptación de los pueblos indígenas. Los indios y sus repúblicas eran libres por un derecho irrenunciable y solamente se podía ejercer un legítimo dominio jurisdiccional si éstos voluntariamente lo aprobaban, un dominio que, por otro lado, debía estar limitado por pactos y contratos establecidos entre la Corona y las repúblicas indianas. Las Casas también defendería un proyecto de monarquía en el que, siguiendo el modelo del gobierno mixto, pudieran convivir la potestad suprema en manos del emperador con la libertad y autonomía de las repúblicas que constituían los reinos de esta metaentidad, particularmente las americanas.

Finalmente, Juan Zapata y Sandoval pertenece a los autores tardíos de la Segunda escolástica. Los cambios introducidos dentro de la teología por los teólogos jesuitas del último tercio del siglo XVI y principios del siglo XVII fueron determinantes en su filosofía. Gracias a ellos, encontramos en Zapata y Sandoval un lenguaje más preciso y especializado, con conceptos claramente diferenciados en sus usos, en comparación con los autores de la primera etapa de la tradición mencionada. El único tratado que conocemos de Zapata y Sandoval se centra en el análisis de la justicia y en particular de una de sus formas: la distributiva. A partir de este concepto, abordó problemas relacionados con el gobierno civil y el eclesiástico, dentro de los que destaca el de la repartición de los bienes de la república entre sus miembros y el derecho que éstos tenían a acceder a ellos.

Al igual que los otros dos autores, Zapata y Sandoval consideraba que la potestad civil residía originariamente en la comunidad y era ésta la que lo transfería a los gobernantes. No obstante, en su postura ante los límites de la autoridad, el carácter constitucionalista y republicano de su teoría política pierde fuerza ante la defensa de un poder político con menores restricciones, el cual, si bien debía estar acotado por el derecho natural, el bien común 
y la justicia en sus diversas formas, no se encontraba directamente limitado por la voluntad del pueblo. Existe un cambio significativo en la teoría política de Zapata y Sandoval, del que se desprende en cierta medida su postura ante una autoridad con mayores facultades. A diferencia de Las Casas, por ejemplo, quien consideraba que el gobernante era un rector al que se le delegaban las funciones de administrar la justicia y los bienes de la república, sin que por ello el pueblo perdiera el dominio sobre sí mismo, para Zapata y Sandoval el príncipe recibía toda la potestad de la comunidad, mediante un acto de autorización, para que actuara en su nombre y representación en un sentido jurídico. Es decir, se le instituía para que las acciones que realizara, encaminadas a la preservación de la justicia, fueran hechas en lugar de la república, como si ambos fueran la misma persona. Así, para el agustino, una vez establecida la transferencia de la potestad civil al gobernante, se identificaba plenamente la voluntad del príncipe con la voluntad del pueblo y el bien común. Esto implicaba que quien detentaba la legítima autoridad no necesitaba contar con el consentimiento de los gobernados para tomar decisiones específicas, por ejemplo en materia legislativa o fiscal, y bastaba con que éstas guardaran las formas de la justicia conmutativa y distributiva, y estuvieran encaminadas al bien común, para que tuvieran validez y obligatoriedad.

No obstante, la idea del príncipe que actúa en nombre de la república suponía principios constitucionalistas dentro de su filosofía política. Para Zapata y Sandoval, el poder del gobernante para decidir sobre asuntos públicos no le pertenecía por derecho propio, sino sólo porque había sido autorizado por la comunidad. Esto significaba que ninguna decisión podía tomarse de manera arbitraria, y eran la búsqueda del bien común y la preservación de la justicia — los fines por los que había sido instituido- los últimos referentes para legitimar la acción de un gobernante. Al abordar este asunto, Zapata y Sandoval introdujo en el centro de su análisis el lenguaje de los derechos subjetivos. La justicia era, para él, un acto de la voluntad cuyo fin era establecer la igualdad entre el derecho de una persona y el deber de otra. Trasladado al ámbito político, la justicia conmutativa y la justicia distributiva 
obligaban a la autoridad a preservar los derechos de la república como persona y de los miembros que la constituían. Al designar a los funcionarios de la república y al administrar los bienes comunes - los temas que más preocuparon a Zapata y Sandoval en su tratado-, los gobernantes tenían el deber de conservar el derecho de la comunidad a tener al frente de ella a las personas más dignas, así como de retribuir a quienes por derecho propio lo merecían. Esto tenía particular relevancia en la intervención de Zapata y Sandoval en el espacio controversial indiano. El tratado De iustitia distributiva fue una defensa de los derechos de los nacidos en el Nuevo Mundo a gobernarse a sí mismos y a ser los primeros beneficiados de los bienes del reino; para el agustino, eran los españoles americanos los principales poseedores de tales derechos.

El estudio de cada uno de estos autores resulta en sí mismo relevante, pues, como intenté resumir en los párrafos anteriores, muestra una serie de tensiones y diversas respuestas que dentro de la escolástica hispanoamericana se presentaron al discutir problemas como el origen del poder o los límites de la autoridad. Pero también, al analizarlos en conjunto, saltan a la vista elementos que permiten establecer interpretaciones más generales sobre el desarrollo histórico del pensamiento político de la Nueva España. Ciertamente, los casos abordados en este estudio no son una muestra representativa del ámbito intelectual novohispano. No obstante, el análisis comparativo de los tratados políticos de Veracruz, Las Casas y Zapata y Sandoval puede brindarnos información relevante sobre el desarrollo del pensamiento de carácter republicano y constitucionalista en Nueva España y de su impacto en otras áreas de la vida de esta región de la Monarquía. Para ello, más que discutir la originalidad de cada uno de estos autores, recurro a sus discursos para fijar coordenadas en un mapa que nos muestre lo que se podía decir y hacer en Nueva España a partir de los lenguajes mencionados.

En primer lugar, cabe resaltar nuevamente un asunto relacionado con los aspectos teóricos de la filosofía política de los autores en cuestión. Al analizar sus posturas ante el problema de los límites de la autoridad, podemos observar cómo en la Nueva España se presentó un proceso de moderación de los argumentos 
constitucionalistas y republicanos similar al arriba descrito para el ámbito ibérico. Mientras que en Veracruz y Las Casas existe un peso fundamental de la voluntad de la república en el proceso de supervisión y validación de las acciones del gobernante, Zapata y Sandoval cede ante el reforzamiento de la autoridad del príncipe. Las fuentes y tradiciones de las que partieron los dos primeros para desarrollar sus argumentos constitucionalistas, el nominalismo y textos vinculados a la tradición neorromana, respectivamente, se vieron limitados dentro de la teología hispánica hacia fines del siglo XVI, en la que imperó un tomismo ortodoxo. Esto provocó que, si bien Zapata y Sandoval hizo un uso de conceptos y teorías más sistemático y especializado, hubiera un claro empobrecimiento en la diversidad de fuentes y lenguajes presentes en su disertación. A la larga, el cambio que se manifiesta en el pensamiento de los tres autores, dentro de un proceso generalizado, contribuyó a la decadencia de la reflexión política de la escolástica hispanoamericana, que pasó de ser una de las tradiciones más fructíferas y conocidas dentro de la filosofía política occidental, durante el siglo XVI y principios del XVII, a ocupar un lugar marginado en relación con otras desarrolladas en Europa, para finales del setecientos.

Otro asunto que merece destacarse al analizar el pensamiento de los tres autores en conjunto es el relativo al uso de la teoría de los derechos subjetivos. El surgimiento en el lenguaje político de la idea de que los seres humanos - y otras entidades- son sujetos de derechos, entendidos como poderes, libertades o facultades que intrínsecamente les pertenecen, es un asunto trascendental en el desarrollo de la filosofía occidental, que permitió, entre otras cosas, el posterior surgimiento de la idea de derechos humanos. Si bien el origen de la teoría de los derechos subjetivos puede ubicarse en ciertas polémicas de la escolástica medieval, fue durante el siglo XVI y en su transición al XVII cuando cristalizó y los autores de la Segunda escolástica jugaron un papel central en ello. Veracruz, Las Casas y Zapata y Sandoval incorporaron a sus tratados el lenguaje de los derechos subjetivos y en el uso diferenciado que hacen de él pueden observarse algunas etapas de su desarrollo. Mientras que en los textos de Veracruz aparece 
de manera sutil, en los de los otros dos ocupa un lugar central de su argumentación. Las Casas lo utilizó para postular la libertad como un derecho ínsito de los indios y sus repúblicas, atribuyéndola probablemente por primera vez a pueblos no europeos, mientras que Zapata y Sandoval lo hizo para defender la prioridad en los derechos de los americanos sobre los europeos para acceder a puestos de gobierno y disfrutar de los bienes de sus repúblicas. La integración del término ius como elemento subjetivo al discurso de ambos autores representa una manifestación temprana del uso de un concepto que se volvería clave en la filosofía moral y política de Nueva España y del resto de Occidente.

Tratando en concreto sobre la controversia indiana, al observar la forma en que los tres autores echaron mano de las teorías republicanas y constitucionalistas para argumentar dentro de ella, se hace evidente un cambio fundamental entre el pensamiento de Las Casas y Veracruz, por un lado, y el de Zapata y Sandoval, por otro. Este cambio fue el desplazamiento del sujeto a reivindicar dentro de la Monarquía: los indios, para los primeros dos; los nacidos en América, particularmente la élite criolla, para el último. Las posturas que asumieron estaban fundadas en su concepción sobre cómo se constituían políticamente las Indias, sobre quiénes componían, en esencia, las repúblicas americanas de la Monarquía. Para Las Casas y Veracruz, eran los indígenas quienes poseían el legítimo dominio sobre sí mismos y sobre la tierra que habitaban: a ellos pertenecía el Orbe Indiano. Los europeos habían arribado a un mundo previamente conformado, con sus propias repúblicas y organización política. Si querían formar parte de él y, sobre todo, si se pretendía incorporarlo a la Monarquía hispánica, debían respetar la base de su constitución y contar con el consentimiento de sus legítimos señores. Zapata y Sandoval, en cambio, tenía en mente un Nuevo Mundo cuyas repúblicas, sujetas ya a la autoridad de la Corona, las componían los nacidos en él, los descendientes de los antiguos habitantes indígenas y de los conquistadores y "primeros pobladores" españoles.

Zapata y Sandoval puede ser visto como un puente entre dos tradiciones constitucionalistas que contribuyeron a dotar de sentido al Nuevo Mundo y a sus actores políticos, entre quienes 
consideraron a los pueblos indígenas como la parte constitutiva de las Indias, por un lado, y quienes ubicaron a los criollos en dicho lugar, por otro. El agustino reconocía que en algún momento los indios fueron los únicos señores de estas tierras y que tuvieron repúblicas legítimamente instituidas. Asimismo, reivindicaba en su tratado los derechos de los indios novohispanos incorporados al nuevo orden. Como una excepción dentro del grupo de criollos que pidieron a la Corona un cambio en la forma de administrar los territorios americanos, Zapata y Sandoval no se valió de la denuncia al maltrato de los pueblos indígenas como un argumento retórico para demostrar el mal gobierno de las autoridades españolas, sino que incluyó entre sus principales demandas los derechos de los indios, en particular el acceso a los cargos civiles y eclesiásticos. En términos ideales, Zapata y Sandoval presentaba a la sociedad indiana como un cuerpo orgánicamente integrado por criollos, indios y los descendientes de ambos. Para el autor, era la ciudadanía definida por la pertenencia a la tierra lo que permitía a estos grupos ser partícipes del orden político. El bien común, por el cual se justificaba la existencia del poder político, era el bien de todos en su conjunto. Esta postura la asumía Zapata y Sandoval al ubicar a las comunidades indianas en su relación con la Corona y con los españoles peninsulares, pero al tratar sobre las repúblicas de Nueva España en sí mismas, sobre la relación entre quienes las conformaban, el bienestar de los descendientes de los conquistadores y sus derechos se superponían al del resto de la población; el bien común ya no era el de toda la república sino el de una de sus partes.

Así pues, si en su postura ante la constitución política del Nuevo Orbe consideramos a Zapata y Sandoval como un puente, en un extremo se ubicaría la tradición de autores como Veracruz y Las Casas y en el otro la que finalmente se volvería dominante en el discurso político de la élite criolla: aquella que ubicaba al indígena como una entidad pasiva dentro de la república y, en cierto sentido, ajena a ella; como un objeto que requería del cuidado y protección de los gobernantes, pero que al mismo tiempo representaba un bien que podía ser aprovechado por quienes tuvieran el derecho sobre él. De esta manera, los indígenas novohispanos 
no sólo fueron desplazados del centro de la vida pública de los reinos de las Indias, sino que también fueron marginados del discurso político. En los siglos XVII y XVIII, algunos autores criollos recuperarían la figura del indígena antiguo, con el fin de construir una historia propia de las tierras americanas, de la que se sentían herederos, y con ello defender su posición dentro de la Monarquía. Pero los indígenas que formaban parte del orden colonial no volvieron a ocupar un lugar central en las reivindicaciones de los pensadores novohispanos, al menos no como lo habían hecho en los tratados de Las Casas y Veracruz.

Cabe preguntarse, finalmente, qué relevancia e implicaciones tuvieron las demandas constitucionalistas y republicanas de los autores que, como Zapata y Sandoval, Veracruz y Las Casas, defendieron los derechos de las repúblicas de Indias dentro de la Monarquía, o si hubo una relación entre éstas y el desarrollo de la vida política e institucional de Nueva España. Para responder estos interrogantes sería necesario elaborar otro trabajo centrado en el análisis de discursos y prácticas más amplias, que contemplara a otros grupos que constituyeron la sociedad novohispana y las instituciones en torno de las cuales se organizaron para buscar resguardar sus intereses, por ejemplo los cabildos de pueblos indígenas y españoles. A reserva de ello, me gustaría presentar un par de reflexiones a manera de hipótesis.

La primera tiene que ver con el problema del gobierno de los pueblos indígenas y el lugar que ocuparon dentro de la Monarquía. A pesar del fracaso del proyecto de continuidad y autonomía de los antiguos señoríos, planteado por Veracruz y Las Casas, el debate en torno a la justicia de la conquista y a la organización política de las Indias contribuyó a que a las comunidades indígenas se les reconociera un espacio en el orden político. Probablemente la consecuencia más importante, en este sentido, fue el establecimiento de los cabildos en las repúblicas de indios. Dichas instituciones permitieron que, hasta cierto punto, se ejerciera el autogobierno, al quedar en los indígenas la capacidad de elegir a sus gobernantes, impartir justicia, administrar los bienes comunales y legislar, siempre y cuando las leyes y sus acciones no fueran en contra de los intereses de la Corona y los principios del catolicismo 
y el derecho natural. A diferencia de lo que buena parte de la historiografía tiende a presentar, las comunidades indígenas de Nueva España - y quienes las componían - no fueron entidades pasivas dentro del orden político, sino agentes que supieron aprovechar, dentro de un contexto marcado por la explotación, las concesiones otorgadas por la Corona para defender sus intereses.

Por su parte, el grupo que constituía la élite criolla buscó la manera de reivindicar su posición dentro de la Monarquía al demandar un papel protagónico en el gobierno y las actividades económicas de los reinos de Nueva España. En la esfera institucional, nuevamente los cabildos fueron un espacio central donde las élites urbanas encontraron un lugar de representación. Las demandas establecidas por los miembros de los ayuntamientos, presentes en las actas de cabildos y en otros documentos elaborados por la institución, se identifican con los postulados de las obras de autores como Zapata y Sandoval. A finales del siglo XVI y principios del XVII, la idea de que los criollos, especialmente los descendientes de conquistadores y primeros colonos, eran la parte constitutiva de las repúblicas de Indias y que, por lo tanto, debían tener el privilegio de ocupar los cargos civiles y eclesiásticos, así como gozar del beneficio de la tierra y la mano de obra indígena, era un lugar común en los discursos de la élite intelectual y de las oligarquías urbanas de Nueva España. Así, lo que David Brading y otros autores han denominado "patriotismo criollo" no es otra cosa que la forma que terminarían de adquirir los lenguajes republicanos y constitucionalistas de Nueva España y de las Indias hacia fines del siglo XVI. 